\title{
MIMU - MUSEU DE INSTRUMENTOS MUSICAIS DA UFPR
}

\author{
Juarez Bergmann Filho (UFPR, Brasil) juarezbergmann@gmail.com \\ Aloísio Leoni Schmid (UFPR, Brasil) iso@ufpr.br \\ Leandro Henrique Merino Mombach (UFPR, Brasil) mombachhardwood@gmail.com \\ Igor Mottinha Fomim (UFPR, Brasil) fomin@ufpr.br \\ Rodrigo Mateus Pereira (UFPR, Brasil) rodrigomateus@ufpr.br \\ Thiago Correa de Freitas (UFPR, Brasil) tcf@ufpr.br
}

\begin{abstract}
Este artigo trata da criação do programa de extensão universitária "MIMU - Museu de Instrumentos Musicais da UFPR" em várias etapas de implementação. Desde a concepção, partindo de necessidades levantadas juntamente com o curso de Tecnologia em Luteria da UFPR, passando pela estruturação do espaço e projeto e construção de expositores específicos, além da criação de logotipo e website para utilização em ambiente gráfico e virtual, até a aquisição de acervo, via doação ou construção.
\end{abstract}




\section{Introdução}

O presente programa de extensão universitária visa à criação de um espaço exclusivamente dedicado à arte da construção de instrumentos musicais, principalmente aqueles de cordas feitos em madeira, conhecida como Luteria.

Mencione-se, na UFPR, a existência do Museu de Ciências, um projeto de extensão lançado pelo Prof. Euclides Fontoura e que, ao longo de duas décadas, angariou a participação de dezenas de acadêmicos, principalmente ligados ao Setor de Ciências Biológicas. Foram alguns milhares de visitantes, predominantemente de escolas de Curitiba e região, procurando ilustrar ou complementar seus estudos de ciências. A interação estabelecida entre os estudantes da UFPR com a comunidade se mostrou positiva: ajudando a atender uma demanda educacional da sociedade, os estudantes puderam desenvolver as próprias competências, entre elas o senso de responsabilidade.

A ideia do Museu de Instrumentos Musicais surgiu naturalmente, em direta conexão com o pioneirismo da implementação do Curso de Tecnologia em Luteria da UFPR, primeiro deste tipo no Brasil, para que o curso pudesse organizar os instrumentos de produção própria e expô-los juntamente com instrumentos antigos, de forma a completar uma linha condutora didática, em ambiente expositivointerativo, incluindo eventos pedagógicos e musicais. Pretende-se assim, estabelecer na UFPR um acervo permanente, organizado e didaticamente acessível, de instrumentos musicais para que alunos e demais membros da comunidade possam desfrutar e melhor compreender a função e o funcionamento de um instrumento musical, assim como o ofício do luthier. O conhecimento que é objeto do âmbito do Curso de Tecnologia em Luteria, tanto apreendido e ensinado, como produzido, apresenta elevado valor como produto da cultura universal. A ação extensionista da UFPR torna disponível à comunidade em geral o primeiro contato - visual ou, preferencialmente, sonoro e manual - com uma série de instrumentos musicais e todo o seu processo de fabricação que remonta à Idade Média. Assim, deve despertar o interesse geral e ainda angariando o interesse específico de potenciais futuros alunos.

De acordo com o jornal O Globo (2012), a editora Heloísa Fischer, da revista "VivaMúsica!", mapeou 92 projetos de "integração social por meio da prática orquestral" no Brasil, que batizou "cidadania sinfônica". Cita-se como base o El Sistema, da Venezuela, mas sem a centralização administrativa que há lá, idealizado pelo regente José Antonio Abreu. Mas, diz ela, o modelo brasileiro não é centralizado numa instituição, como lá. Somente os projetos liderados pela Sra. Fiorella Solares, viúva do maestro David Machado (antigo colaborador de Abreu) contemplam quase mil alunos. Estes projetos têm por finalidade a cidadania e não a formação de músicos profissionais; no entanto, este efeito surge como nova perspectiva. No momento em que passa a vigorar a obrigatoriedade do ensino de música nas 
escolas, dá-se um primeiro passo no sentido de canalizar esforços do curso de Luteria para uma aproximação com a sociedade.

Atualmente em nosso país, o mercado de consumo de todos os tipos de instrumentos musicais vem se desenvolvendo enormemente. Particularmente nas áreas dos instrumentos de cordas elétricos e acústicos, surgiu uma grande necessidade de profissionais especializados na arte da luteria, assim o Curso de Tecnologia em Luteria da UFPR, tem como um de seus principais objetivos, a formação de especialistas capazes de avaliar e atuar da melhor forma possível em todos os instrumentos da música erudita e popular brasileira. Como profissão definida há mais de 400 anos, a luteria preserva técnicas e tradições muito antigas voltadas a manutenção, restauração e confecção de instrumentos musicais de cordas. Devido ao desenvolvimento de novos materiais e tecnologias de preservação, este ofício deve ser constantemente enriquecido e atualizado. Assim, o aspirante a luthier deve entender que, para a confecção de novos instrumentos, toda a tradição não basta e para a restauração, toda a tecnologia é pouca. Neste sentido o Museu pode servir de ferramenta visual e física da preservação e propagação desta importante tradição, servindo como agente inspirador de futuras gerações de construtores do nosso país. Até o final dos anos oitenta a luteria brasileira vinha sendo mantida por imigrantes oriundos de uma Europa devastada por guerras e dificuldades. Com a estabilidade política, social e econômica do velho continente gradativamente este cenário foi se alterando por completo. Com o desaparecimento destes profissionais, o autodidatismo tomou conta do mercado nacional, algumas vezes prejudicando de forma irreparável nosso patrimônio histórico instrumental. Somente alguns jovens aprendizes mantiveram o trabalho de seus mestres e outros poucos foram se especializar fora do Brasil muitas vezes não mais retornando. Nesta nova etapa da economia brasileira, com a expansão do consumo e exigência maior de profissionais competentes no mercado, a luteria brasileira precisa encontrar soluções para gradualmente criar autonomia e se libertar da dependência de países da Europa e Estados Unidos como fornecedores de equipamentos e acessórios. Hoje o Brasil é considerado um dos maiores mercados de consumo do mundo, com excelentes expectativas para o futuro em todas as áreas que envolvem a luteria.

\section{Estrutura}

Atualmente, o projeto ocupa o espaço do subsolo do Centro de Exposições (Bloco C) do Setor de Educação Profissional e Tecnológica (SEPT) da UFPR, contando, atualmente, com o total de cinco expositores projetados $\mathrm{e}$ construídos especialmente para atender às necessidades e particularidades deste tipo de Museu. Os móveis apresentam estrutura quadrada reforçada, com suas laterais compostas de vidros de $10 \mathrm{~mm}$ de espessura, com buracos para circulação de ar e fixação das barras de ferro que sustentam alguns 


\section{ReLAInEF}

instrumentos pendurados. Suas dimensões foram pensadas a fim de atender a diversos tamanhos de instrumentos musicais. A Iluminação interna individual e conjunto de rodas proporciona maior liberdade na composição do espaço, já que os expositores tornam-se independentes, além disso, quatro gavetas em cada expositor acomodam armazenamento extra.

Um dos objetivos do programa é manter um espaço permanente para a exposição, divulgação e consequentemente valorização do curso de Tecnologia em Luteria, assim, alunos e professores dividem seus trabalhos de construção juntamente com outros construtores do passado. Desta forma, acreditamos que o aluno sentirá seu trabalho valorizado e consequentemente gerará comprometimento e aumentará a qualidade e a motivação de seu labor.

FIGURA 1 - ESPAÇO OCUPADO PELO PROGRAMA E SEUS EXPOSITORES.

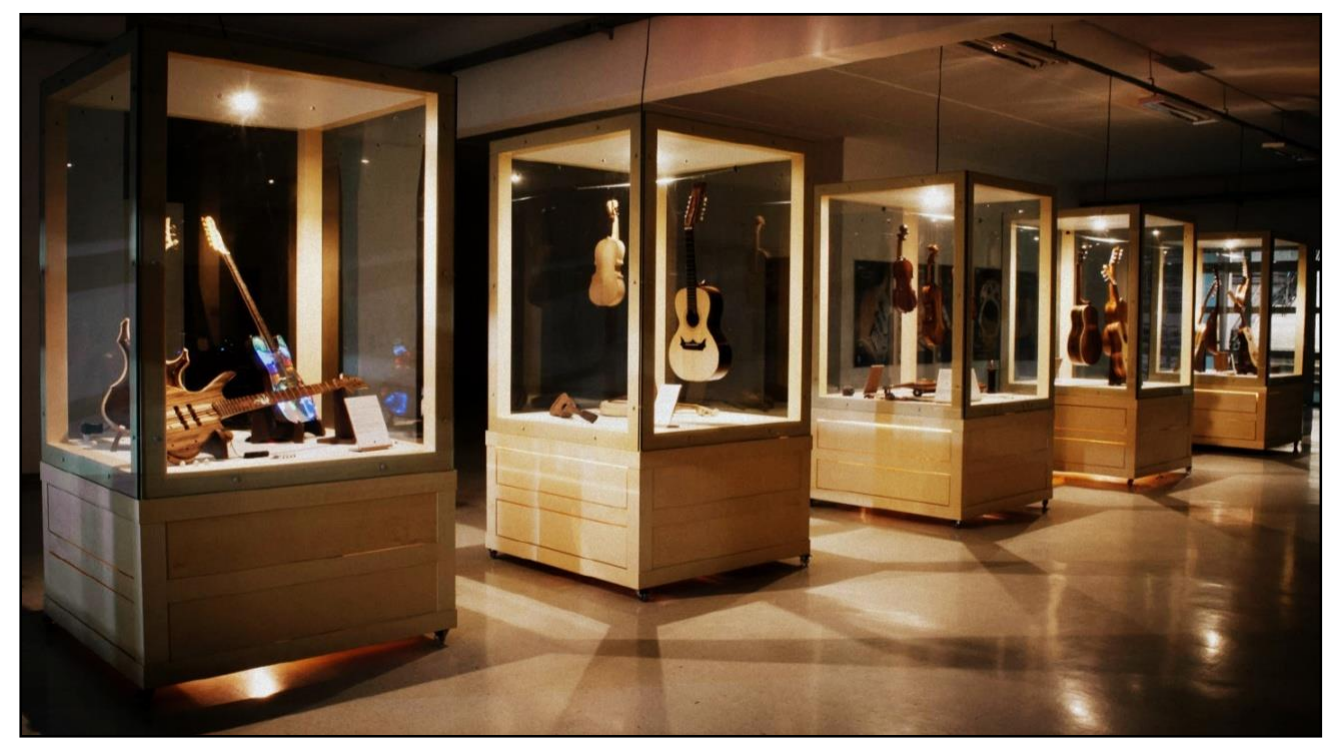

Fonte: Os autores (2012) 


\section{ReLAInEP}

\section{FIGURA 2 - DETALHE DO EXPOSITOR - BAIXO ELÉTRICO - RODRIGO MATEUS PEREIRA, GUITARRA FOREST - ANDRÉ DEBIAZIO, GUITARRA TELEDCASTER - BRAYAN AMORIM}

3.

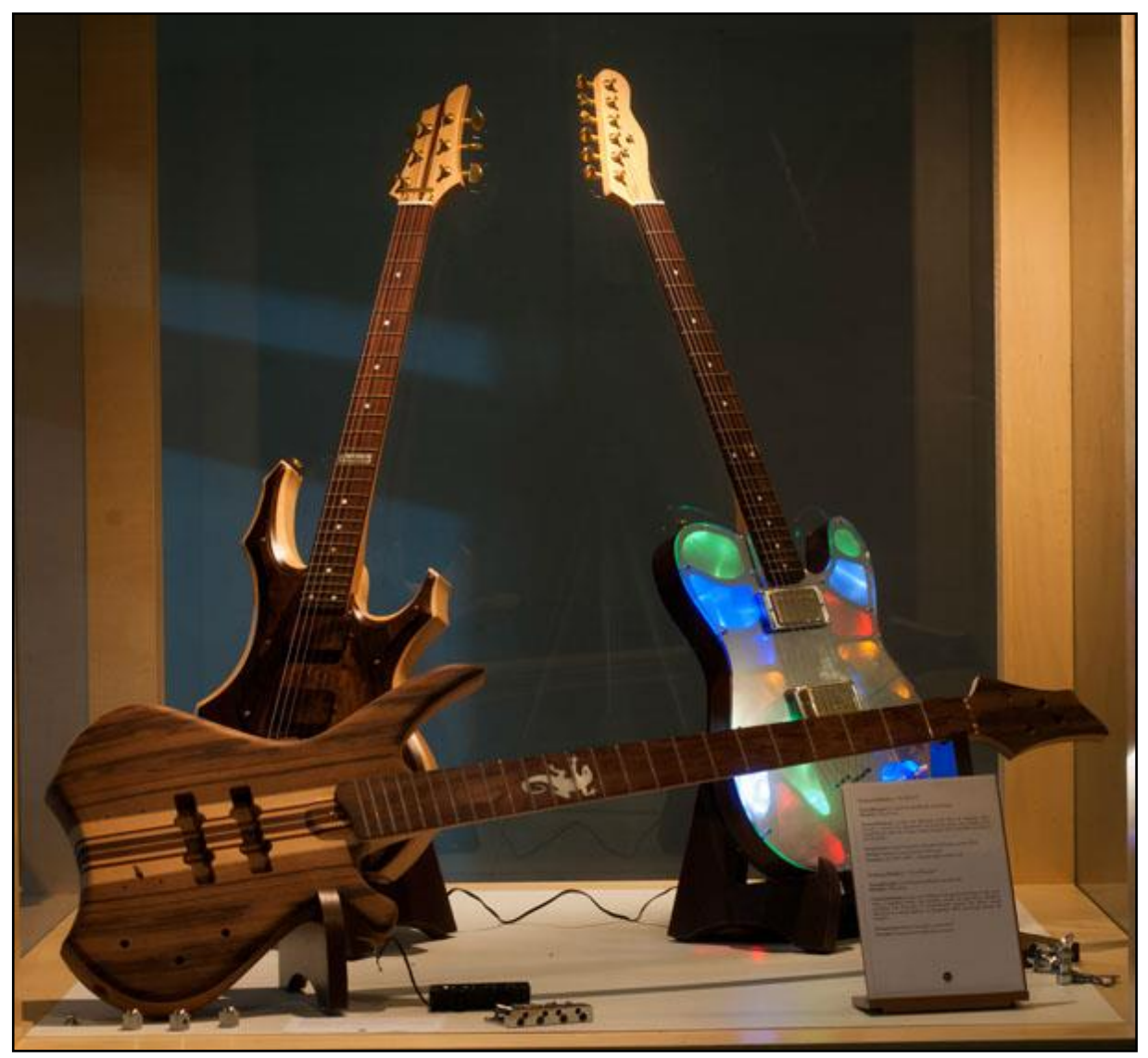

Fonte: Os autores (2012)

4. Planejamento gráfico: impresso e em ambiente virtual

Em conjunto com a estrutura física do museu, o projeto também foi concebido para funcionar em ambiente virtual e impresso, atuando assim em diversas mídias de divulgação. Para tanto, o primeiro passo foi criar uma logomarca que caracterizasse o MIMU tanto em impressões gráficas quanto em web-sites e outras mídias digitais. Assim, decidiu-se por uma logo que simples, direta, monocromática e que obviamente remete-se ao universo e à cultura de instrumentos musicais, chegando-se às seguintes versões finais: A logo completa que remete à boca, a escala e as cordas de um violão, e a versão reduzida, para melhor comportar certos tipos de mídia e espaço. 
FIGURA 3 - LOGO DO MUSEU - VERSÃO COMPLETA
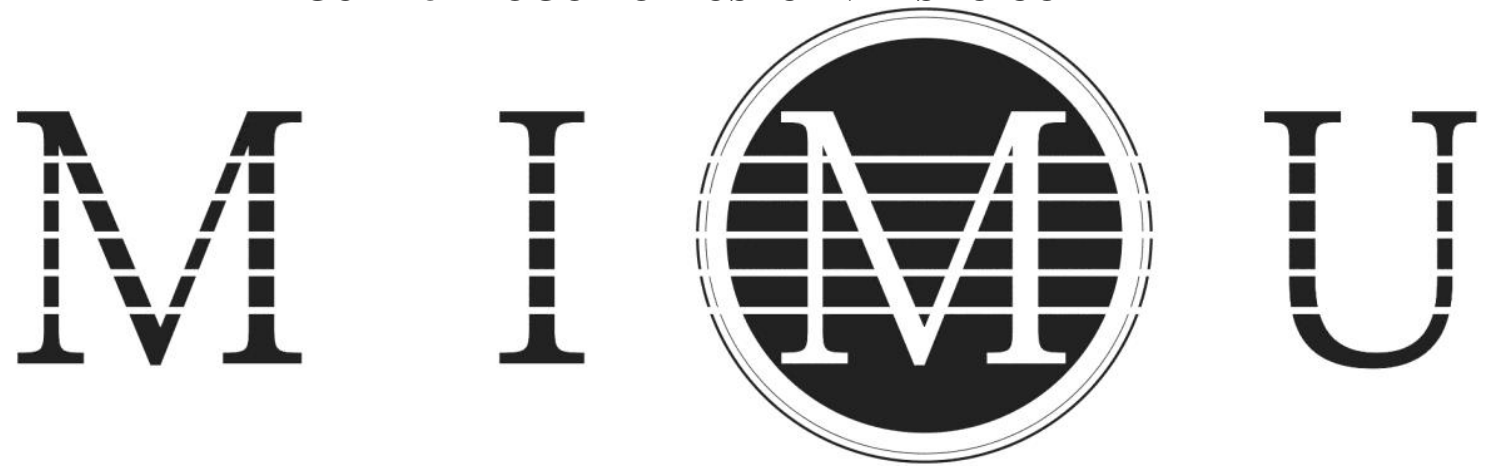

\section{Museu dos Instrumentos Musicais • UFPR}

Fonte: Os autores (2012)

Também deve-se destacar a criação do website do programa, www.mimu.ufpr.br e da página do facebook, www.facebook.com/mimu.ufpr. Tanto o website quanto a página do facebook foi concebida para aproveitar todo o potencial de divulgação que o ambiente virtual e redes sociais oferece, em um layout simples, direto e intuitivo. Este tipo de mídia permite que o programa ofereça muito mais informações que o ambiente físico, com fotos de exposições passadas,assim como detalhamentos dos instrumentos, com fotos, histórico e futuramente arquivos de áudio e vídeo digitais.

\section{Acervo}

Um dos desafios de qualquer projeto museológico é a aquisição e manutenção de um acervo interessante, diversificado e enriquecedor. Aproveitando o potencial que o curso de Luteria oferece, priorizamos a construção de instrumentos musicais que relacionassem com o conteúdo trabalhado no curso, não somente os cordófonos, instrumentos obviamente ligados à Luteria, mas também aerófonos e instrumentos experimentais. O foco principal do curso, em termos de construção, são os violinos, violões e a guitarras elétricas. Assim, no processo de aquisição do acervo do MIMU, naturalmente surgiu o interesse pela pesquisa e construção destes instrumentos e seus ancestrais, com o intuito de que servissem de ferramentas didáticas e históricas, para que pudéssemos melhor entender a evolução de cada um destes ramos da Luteria. Por consequência disto, construímos e expomos, por meio de extensivo trabalho de pesquisa histórica e de reconstrução, alguns instrumentos raros, muitos deles únicos no Brasil, como por exemplo: duas rabecas medievais, uma vielle renascentista, uma lira da Braccio, além de uma pesquisa preliminar na construção de violinos, violas e arcos com madeiras alternativas brasileiras, assim como guitarras barrocas, violões de diversos tipos, violas brasileiras e guitarras portuguesas. 


\section{ReLAInEP}

\section{FIGURA 4 - OUD EGÍPCIO - ACERVO: MIMU FOTO: JUAREZ BEGMANN FILHO}

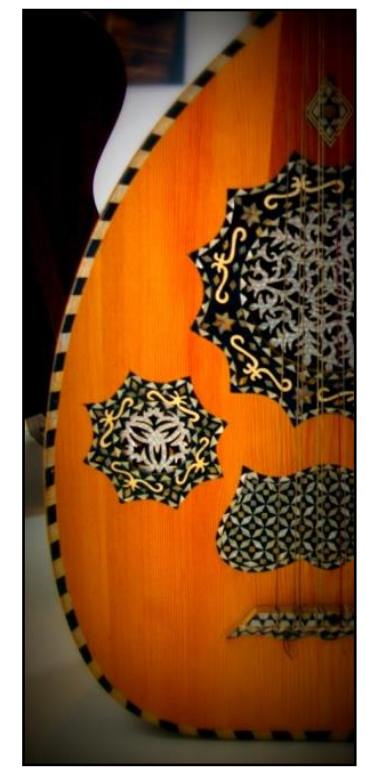

Fonte: Os autores (2012)

FIGURA 5 - VIOLA DO ANJO - E DETALHE DA VOLUTA - LEANDRO MOMBACH -
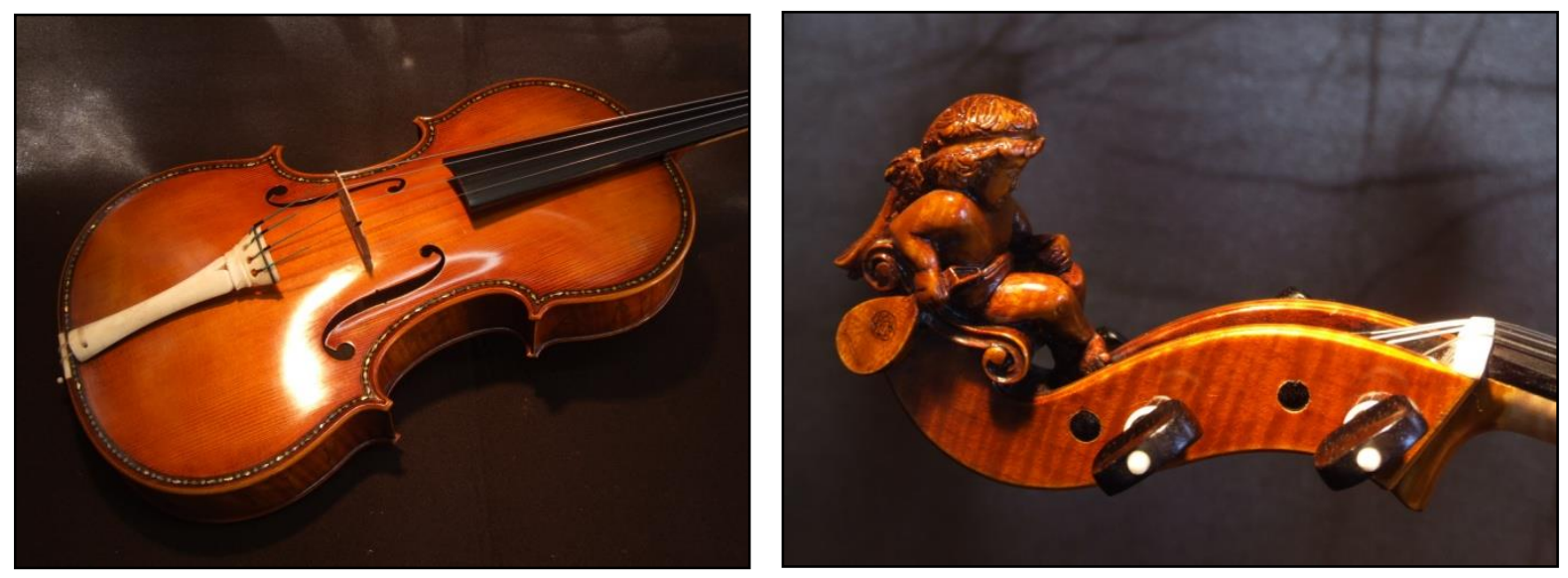

Fonte: Os autores (2012)

Tem destaque na exposição de abertura a Viola do Anjo, do luthier Leandro Mombach, que foi o idealizador do Curso. Trata-se do instrumento de número 50 da produção do luthier. Viola na concepção tradicional, apresenta como diferencial comemorativo a filetagem em madrepérola e osso; o estandarte em osso; as inscrições douradas do facho; e, principalmente, o entalhe da voluta em forma de anjo, com traços Guarani, portando alaúde, em oportuna menção ao encontro de uma tradição que é árabe (o alaúde ou lute, de onde vem o próprio nome do ofício da Luteria), européia no refinamento da sua técnica principalmente no período barroco, e chega ao Brasil com a colonização. Prestigia, ainda, a cultura dos povos nativos do Brasil e, talvez, o episódio de sua educação musical, trabalho 
aniquilado quando da violenta expulsão da Companhia de Jesus de Portugal, Espanha e suas colônias pelo Marquês de Pombal. Este instrumento demonstra aos alunos um patamar de realização técnica e artística estabelecido pelo idealizador do curso e, hoje, seu professor.

Atualmente o MIMU também recebeu a doação de importantes e raros instrumentos musicais, como um oud egípcio, um charango boliviano, um violão-alaúde alemão do século XIX assim como duas bandurrias espanholas, uma delas do renomado luthier madrilenho, José Ramirez. Também é uma preocupação do MIMU a divulgação e o incentivo à cultura regional popular brasileira, sobretudo a paranaense, com exemplares de rabecas caiçaras, importante instrumento do fandango paranaense assim como violas caipiras. Dentre os aerófonos, destacam-se flautas renascentistas feitas em diversas madeiras brasileiras, além de um raro instrumento de palheta dupla chamado cervelato. Destacamos aqui, acessórios sortidos antigos, entre cordas para violino e violão, breu para crinas de arco e ferramentas para construção, as mais antigas datadas do final do século XIX.

\section{Formas de utilização e integralização de atividades}

Estão previstas, no âmbito do Programa de Extensão, diversas ações de interesse público e que se constituem em atividades formativas ofertadas aos alunos do curso de Luteria e, potencialmente, outros: mostra permanente, cuja organização, documentação e apresentação deve ser continuamente aperfeiçoada, inclusive as técnicas de Museografia;

mostras temporárias e temáticas: potencializando oportunidades como datas comemorativas, visitas, trabalhos de pesquisa acadêmicos, empréstimo de acervos; eventos científicos e de divulgação: o Museu se presta a um encontro de construtores de instrumentos que deve acontecer no âmbito do Curso de Luteria da UFPR, oferecendo a construtores de instrumento da região a oportunidade para tornar conhecido seu trabalho aos círculos acadêmicos que, por sua vez, terão oportunidade de registro.

\section{Comentários finais}

O Museu teve seu lançamento durante a Feira de Cursos e Profissões da UFPR em setembro de 2012. Apesar de não ter sido feita divulgação específica, centenas de pessoas que vieram à Feira estiveram no espaço do Museu e dezenas deles assinaram o livro de visitantes. Sem um levantamento sistemático, já foi possível registrar alguns aspectos relevantes deste programa de extensão universitária:

- ineditismo no estado do Paraná, e no Brasil

- reforço à identidade do Curso de Luteria e de seus alunos, docentes e técnicos envolvidos direta ou indiretamente

- desenvolvimento de um senso de responsabilidade dos alunos 


\section{ReLAInEF}

empenhados em construir
instrumentos musicais de
qualidade, sabendo da
perspectiva de expô-los assim
que prontos para os visitantes.
Próximos passos incluem a
aquisição de três novas
unidades de expositores, a
finalização de um catálogo
impresso, em cores e o
aprimoramento do website,
possibilitando
implementação de visitas
sistemáticas.

\section{Referências}

ABRASHEV, B.; GADJEV, V. The Illustrated Encyclopedia of Musical Instruments. Sofia: Köneman, 2006.

AUSONI, A. Music in Art. Los Angeles: Getty Publications, 2009, 2009.

BAINES, A. (Ed.). Musical Instruments Through the Ages. Londres: Penguin Books, 1969.

BURKE, P. Hibridismo Cultural. São Leopoldo: Editora Unisinos, 2003.

CANDÉ, R. D. História Universal da Música. São Paulo: Martins Fontes, v. II, 2001.

CUMPIANO, W.; NATELSON, J. Guitarmaking: Tradition and Technology. Nova Iorque: Chronicle Books, 1993.

FABER, T. Stradivarius: Cinco Violinos, Um Celloe e Três Séculos de Perfeição. Rio de Janeiro: Record, 2006.

GROUT, J. D.; PALISCA, V. C. História da música ocidental. São Paulo: Gradiva, 2007. fraud: deception, forgery, theft, and lawsuits in England and America. Londres: Clarendon Press, 1997.

JONES, S. S. The Lira da Braccio. Bloomington: Indiana University Press, 1995.

KNIGHTON, T.; FALLOWS, D. Companion to Medieval and Renaissance Music. Los Angeles: University of California Press, 1997.

KOLNEDER, W. The Amadeus Book of the Violin - Construction, History and Music. Portland: Amadeus Press, 1998.

NOAD, F. The Baroque Guitar. [S.l.]: Ariel Publications, 1974.

OLIG, B.; WALLISCH, H. Enciclopédia dos Instrumentos Musicais. Lisboa: Centralivros, 2004.

PAGANELLI, S. Musical Instruments from the Renaissance to the 19th century. Feltham: Hamlyn Publishing, 1970.

RAULT, L. Musical Instruments: Craftsmanship and Tradition from Prehistory to the Present. Nova Iorque: Harry Abrams, 2000.

REMNANT, M. Musical Instruments of the West. Londres: B. T. Batsford Limited, 1981.

REMNANT, M. Musical Instruments - An Illustrated History From Antiquity to the Present. Londres: B. T. Batsford Ltda., 1989.

ROMANELLI, G. G. A rabeca do fandango paranaense: a busca de uma origem utilizando o violino. I Simpósio de Pesquisa em Música., Curitiba, 2005. 1-9.

SACHS, C. The History of Musical Instruments. Mineola: Dover, 2006.

SANDBERG, L. The Acoustic Guitar Guide. $2^{\underline{a}}$ Edição. ed. Atlanta: A Capella Books, 2000 .

SENNETT, R. O Artífice. Rio de Janeiro: Record, 2009. 


\section{ReLAInEP}

TYLER, J.; SPARKS, P. The guitar and its music: from the Renaissance to the Classical era. Oxford: Oxford University Press Inc., 2002.

VENTURA, M. Orquestras sociais se multiplicam no Brasil, mudando o destino de jovens carentes. http: //oglobo.globo.com, agosto 2012. Disponivel em: <http://oglobo.globo.com/cultura/orquestrassociais-se-multiplicam-no-brasil-mudandodestino-de-jovens-carentes-5787491>. Acesso em: 20 agosto 2012.

VERSARI, A. Il Museo della Musica: Strumenti Italiani nei Secoli. Veneza: Edizioni Novecento.

WHITELEY, J. Stringed Instruments In the Ashmolean Museum. Oxford: Henry Ling Ltd., 2008.

WINTERNITZ, E. Musical Instruments and their Symbolism in Western Art. $1^{\underline{a}}$ Edição. ed. Nova Iorque: W.W. Norton \&
Company, 1967.

\section{Agradecimentos}

À Professora Helena Fernanda Graf, do Departamento de Construção Civil da UFPR, pelo projeto dos expositores. À designer gráfica Tatiana Ogassawara pela sua ajuda na criação da Logo do Museu. Aos proprietários dos instrumentos recebidos em doação. Aos alunos bolsistas do programa de extensão do Museu dos Instrumentos Musicais da UFPR, Bogdan Skorupa dos Santos, Josielly de Mello, Jonathan Schütz e Henry Maas, por todo o esforço e dedicação a este projeto. 